ARTICLE

https://doi.org/10.1038/s41467-019-10157-5

\title{
Covalent organic framework membranes through a mixed-dimensional assembly for molecular separations
}

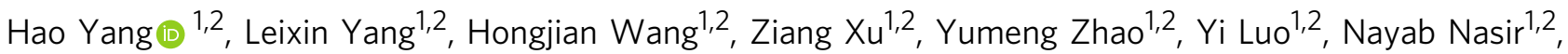
Yimeng Song ${ }^{1,2}$, Hong Wu $\mathbf{W}^{1,2,3}$, Fusheng Pan $^{1,2} \&$ Zhongyi Jiang ${ }^{1,2}$

Covalent organic frameworks (COFs) hold great promise in molecular separations owing to their robust, ordered and tunable porous network structures. Currently, the pore size of COFs is usually much larger than most small molecules. Meanwhile, the weak interlamellar interaction between COF nanosheets impedes the preparation of defect-free membranes. Herein, we report a series of COF membranes through a mixed-dimensional assembly of $2 \mathrm{D}$ COF nanosheets and 1D cellulose nanofibers (CNFs). The pore size of $0.45-1.0 \mathrm{~nm}$ is acquired from the sheltering effect of CNFs, rendering membranes precise molecular sieving ability, besides the multiple interactions between COFs and CNFs elevate membrane stability. Accordingly, the membranes exhibit a flux of $8.53 \mathrm{~kg} \mathrm{~m}^{-2} \mathrm{~h}^{-1}$ with a separation factor of 3876 for $\mathrm{n}$-butanol dehydration, and high permeance of $42.8 \mathrm{~L} \mathrm{~m}^{-2} \mathrm{~h}^{-1}$ bar ${ }^{-1}$ with a rejection of $96.8 \%$ for $\mathrm{Na}_{2} \mathrm{SO}_{4}$ removal. Our mixed-dimensional design may inspire the fabrication and application of COF membranes.

\footnotetext{
${ }^{1}$ Key Laboratory for Green Chemical Technology of Ministry of Education, School of Chemical Engineering and Technology, Tianjin University, Tianjin 300072, China. ${ }^{2}$ Collaborative Innovation Center of Chemical Science and Engineering (Tianjin), Tianjin 300072, China. ${ }^{3}$ Tianjin Key Laboratory of Membrane Science and Desalination Technology, Tianjin University, Tianjin 300072, China. Correspondence and requests for materials should be addressed to H.W. (email: wuhong@tju.edu.cn) or to F.P. (email: fspan@tju.edu.cn) or to Z.J. (email: zhyjiang@tju.edu.cn)
} 
T wo-dimensional (2D) materials are promising molecular building blocks for separation membranes owing to their atomic thickness with minimized transport resistance as well as extraordinary physicochemical properties ${ }^{1,2}$. The $2 \mathrm{D}$ materials-based separation membranes hold great promise in energy and environment-relevant applications such as carbon capture $^{3}$, bio-alcohol fuel production ${ }^{4}$, water purification and desalination ${ }^{5}$. As a kind of crystalline porous materials, 2D covalent organic frameworks (COFs) from the atomically precise integration of organic units have drawn tremendous attention in recent years ${ }^{6,7}$. The well-defined pore aperture, ordered onedimensional (1D) nanochannels, readily tailored functionalities together with superior chemical stability, make 2D COFs excellent candidates for constructing new-generation membranes ${ }^{8,9}$. Compared with graphene oxide (GO) membranes, which are primarily prepared by filtration of GO laminates and separate targeted molecules primarily relying on the interlayer spacing $^{10,11}$, the 2D COF membranes could achieve ultrafast and highly selective separation by their abundant and well-organized in-plane nanopores as well as rigid skeletons ${ }^{12}$. Moreover, nanoporous COFs could offer more available monomers and assembling methods due to their structural diversities compared with the impermeable GO. However, at present there are only a few reports pertaining to $2 \mathrm{D}$ COF membranes for separation of small molecules ${ }^{13,14}$. One major reason may arise from the inferior sieving effects because the pore size $(0.8-4.7 \mathrm{~nm})^{15}$ of chemically stable COFs (such as Schiff-base-type ${ }^{16}$ and triazinetype $\left.\mathrm{COFs}^{17}\right)$ is larger than the kinetic diameter of most small molecules like water $(0.26 \mathrm{~nm}), \mathrm{CO}_{2}(0.33 \mathrm{~nm})$ and $\mathrm{C} 1-\mathrm{C} 4$ alcohols $(0.38-0.51 \mathrm{~nm})$. The accurate tuning of sub-nanometer pore size in COFs proves difficult by either monomer design or group modification ${ }^{7,18}$. Besides, fabricating COF membranes by assembling 2D COF nanosheets remains a great challenge. Particularly, the weak interlamellar $\pi-\pi$ interactions between assembled COF nanosheets usually result in the poor mechanical strength of the COF membranes ${ }^{8,14}$. It is imperative to explore an effective approach to simultaneously implement the effective pore size adjustment and mechanical strength enhancement of COF membranes.

The embedment of suitable components into the interlayers of COF nanosheets can be an efficient way to manipulate their stacking behaviors ${ }^{14}$, and consequently the structures and properties of COF membranes. Recently, the emergence of mixeddimensional heterostructures $(2 \mathrm{D}+n \mathrm{D}$, where $n$ is 0,1 or 3$)$ has opened avenues for fundamental scientific topics and applied device designs ${ }^{19}$, which inspires us to design COF membranes with high performance by a mixed-dimensional strategy. Among them, the $2 \mathrm{D}+1 \mathrm{D}$ design is expected an effective approach to adjust the pore size of COF membranes. 1D materials with highly anisotropic shape are considered as potential candidates to decrease the size of pore entrance by covering onto the surface of COF nanosheets (sheltering effect) without the significant sacrifice of permeability of COF membranes. To enhance the mechanical strength of COF membranes, the $1 \mathrm{D}$ components should possess abundant active sites and generate robust linkage with COFs through multiple interactions.

Herein, we propose a kind of COF membranes using 2D COF nanosheets and $1 \mathrm{D}$ cellulose nanofibers $(\mathrm{CNFs})$ as building blocks. CNFs, with 1D shape derived from plants, are one of the strongest natural materials owing to their hydrogen-bonded parallel chains ${ }^{20,21}$, and the abundant hydroxyl groups on their surface can be conveniently utilized for subsequent functionalization. The mixed-dimensional nanocomposites comprising COF nanosheets covered by CNFs are first prepared and then assembled into the densely interlocked COF membranes in one-step. The sheltering effect of CNFs reduces the size of pore entrance of
COF nanosheets and also establishes robust interlamellar microporous networks. The interlamellar equivalent micropore size in membranes can be tailored and the molecular sieving has been intensified, where smaller molecules pass through while larger ones are rejected ${ }^{22}$. Furthermore, the multiple interlamellar interactions render the COF membranes high mechanical strength. The resulting membranes exhibit superior performance in solvent dehydration, dye rejection and salt rejection. The mixed-dimensional design in our study is broadly applicable, which provides a general toolbox for designing robust COF membranes with high performance.

\section{Results}

Mixed-dimensional assembly of 2D COFs and 1D CNFs. A Schiff-base-type $\mathrm{COF} \mathrm{TpTG}_{\mathrm{Cl}}$ was synthesized by 1,3,5-triformylphloroglucinol (Tp) and triaminoguanidinium chloride $\left(\mathrm{TG}_{\mathrm{Cl}}\right)$ and used as the $2 \mathrm{D}$ component ${ }^{23,24}$. The $\mathrm{COF} \mathrm{TpTG}_{\mathrm{Cl}}$ can be easily exfoliated to obtain chemically stable nanosheets. Meanwhile, the intrinsic positive charge of guanidinium units on $\mathrm{TpTG}_{\mathrm{Cl}}$ framework makes it a good candidate to fabricate robust nanocomposites by assembling with negatively charged components. TEMPO-oxidized CNFs ${ }^{25}$ with a high density of carboxyl groups were employed as the $1 \mathrm{D}$ components. A schematic diagram of the assembly process of $\mathrm{TpTG}_{\mathrm{Cl}}$ and CNFs is displayed in Fig. 1a. The molecular structure and synthesis procedure of $\mathrm{TpTG}_{\mathrm{Cl}}$ are shown in Supplementary Fig. 1. The transmission electron microscopy (TEM) image (Fig. 1b) shows that the $\mathrm{TpTG}_{\mathrm{Cl}}$ with 1-2 $\mu \mathrm{m}$ of lateral dimension is transparent to the electron beams. The high-resolution TEM (HRTEM) image along with fast Fourier transformation (FFT) and inverse FFT (IFFT) images (Fig. 1c) indicate the high crystallinity of $\mathrm{TpTG}_{\mathrm{Cl}}$ and hexagonal structures of the basal planes. The element distribution mappings and scanning electron microscopy (SEM) image of $\mathrm{TpTG}_{\mathrm{Cl}}$ are shown in Supplementary Figs. 2 and 3. The thickness of $\mathrm{TpTG}_{\mathrm{Cl}}$ nanosheets is around $1.5 \mathrm{~nm}$ measured by atomic force microscopy (AFM) (Fig. 1d). The powder X-ray diffraction (PXRD) pattern and ${ }^{13} \mathrm{C}$ CP-MAS solid-state NMR spectroscopy (Supplementary Figs. 4 and 5) confirm the crystallographic and chemical structure of $\mathrm{TpTG}_{\mathrm{Cl}^{2}}{ }^{23}$. The permanent porosity of $\mathrm{TpTG}_{\mathrm{Cl}}$ was verified by $\mathrm{N}_{2}$ adsorption-desorption isotherms (Supplementary Fig. 6). The measured Brunauer-Emmet-Teller (BET) surface area is $305 \mathrm{~m}^{2} \mathrm{~g}^{-1}$ and the major pore size is 1.3 nm (Supplementary Fig. 7). TEMPO-oxidized CNFs with a diameter of around $2 \mathrm{~nm}$ and a length of $0.5-1 \mu \mathrm{m}$ were observed from the AFM image (Fig. 1e). The stable mixed-dimensional nanocomposites with a planar $\mathrm{TpTG}_{\mathrm{Cl}}$ covered with dense networks of $1 \mathrm{D}$ CNFs (Fig. If and Supplementary Fig. 8) were spontaneously formed by blending the $\mathrm{TpTG}_{\mathrm{Cl}}$ and $\mathrm{CNFs}$ in an aqueous solution. The mixed-dimensional nanocomposites are denoted as $\mathrm{TpTG}_{\mathrm{Cl}} @ \mathrm{CNFs}-\mathrm{X}$, where the serial number $\mathrm{X}=1,2$, $3,4,5,6$ or 7 corresponds to increasing CNF content as shown in Supplementary Table 1 . The TpTG $\mathrm{Tl}_{\mathrm{Cl}} @ \mathrm{CNFs}-\mathrm{X}$ nanocomposites can be easily dispersed in water to form a stable colloidal solution (Fig. $1 \mathrm{~g}$ ), which is a preferential precursor for membrane fabrication. PXRD patterns of the as-prepared $\mathrm{TpTG}_{\mathrm{Cl}} @ \mathrm{CNFs}-\mathrm{X}$ nanocomposites (Supplementary Fig. 9) prove that the crystallographic structures of $\mathrm{TpTG}_{\mathrm{Cl}}$ and $\mathrm{CNFs}$ are unaffected by the assembly. The negatively charged carboxyl groups on CNFs are considered to have been integrated with the positively charged guanidine groups on $\mathrm{TpTG}_{\mathrm{Cl}}$ via electrostatic interactions. The charge carrying properties of the $\mathrm{TpTG}_{\mathrm{Cl}}$ solution and CNFs solution were characterized by zeta potential measurement at different $\mathrm{pH}$ values to confirm the electrostatic interactions (Supplementary Fig. 10). Both the $\mathrm{TpTG}_{\mathrm{Cl}}$ and $\mathrm{CNFs}$ exhibit dominant surface charges when the $\mathrm{pH}$ is in the range of 2 to 6 . 
a
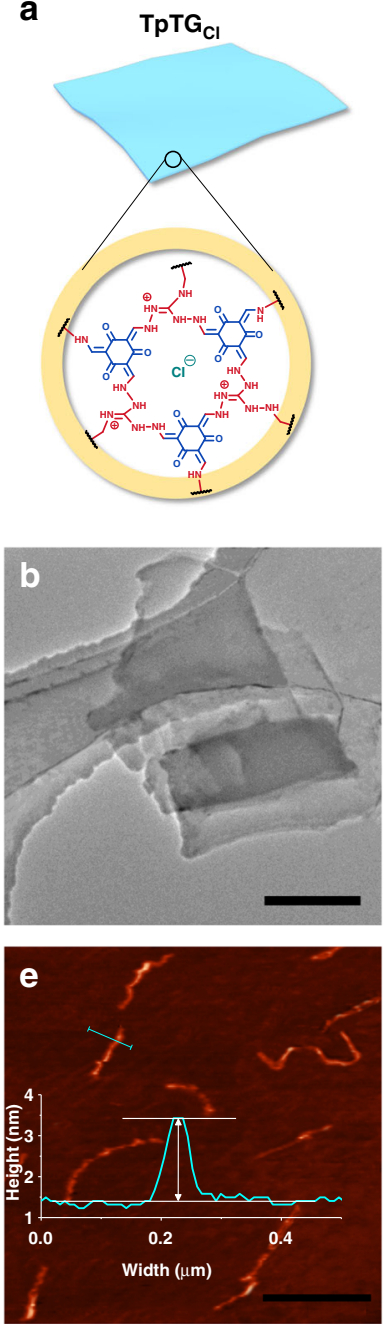

CNFs
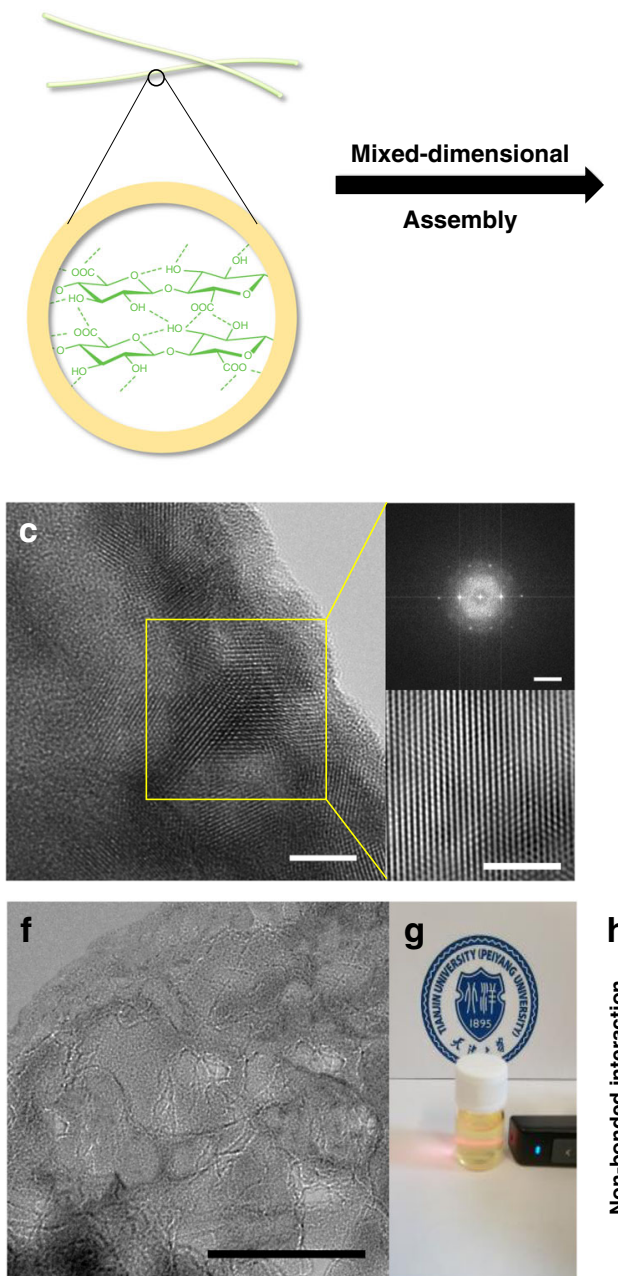
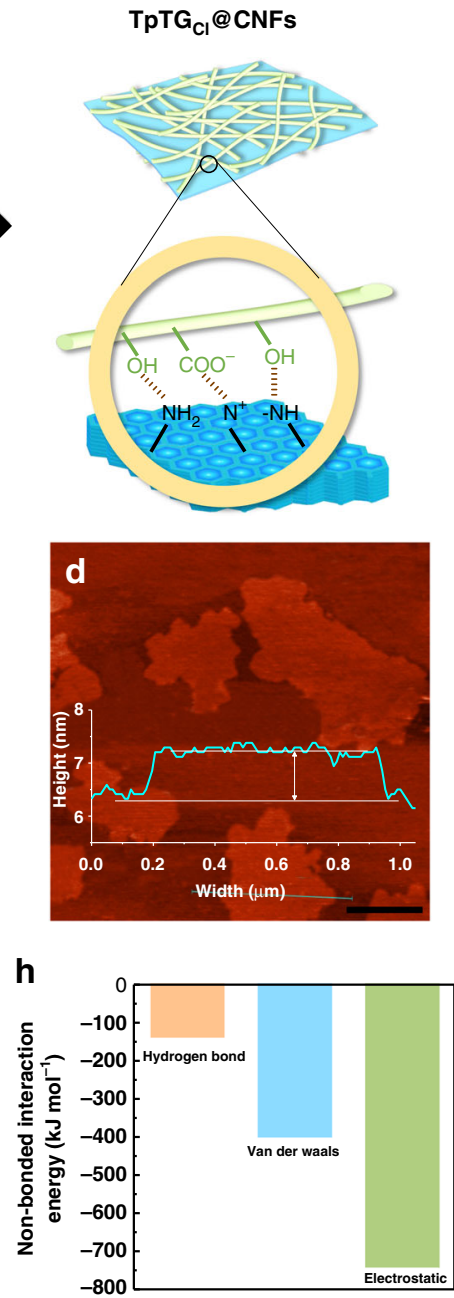

Fig. 1 Mixed-dimensional assembly of $\mathrm{TpTG}_{\mathrm{Cl}}$ and CNFs. a A schematic illustration showing the assembly process and the interactions. $\mathbf{b}$ TEM image of $\mathrm{TpTG}_{\mathrm{Cl}}$ (scale bar, $500 \mathrm{~nm}$ ). c HRTEM image of $\mathrm{TpTG}_{\mathrm{Cl}}$ (scale bar, $5 \mathrm{~nm}$ ) with FFT (top-right, scale bar, $2 \mathrm{~nm}^{-1}$ ) and IFFT images (bottom-right, scale bar, $5 \mathrm{~nm}$ ). d AFM image and height profile of $\mathrm{TpTG}_{\mathrm{Cl}}$ (scale bar, $500 \mathrm{~nm}$ ). e AFM image and height profile of CNFs (scale bar, $1 \mu \mathrm{m}$ ). f TEM image of TpTG ${ }_{C I} @ C N F s-X$ nanocomposites (scale bar, 100 nm). g Tyndall scattering effect in the aqueous solution of TpTG ${ }_{c I} @ C N F s-X$ nanocomposites. h MD simulations of the calculated non-bonded interaction energy between $\mathrm{TpTG}_{\mathrm{Cl}}$ and $\mathrm{CNFs}$

Therefore, the electrostatic interactions between $\mathrm{TpTG}_{\mathrm{Cl}}$ and CNFs can be readily established in near-neutral solutions. Fourier transform infrared spectroscopy (FTIR) and X-ray photoelectron spectroscopy (XPS) were employed to further characterize the interactions between $\mathrm{TpTG}_{\mathrm{Cl}}$ and CNFs (Supplementary Figs. 11 and 12). In addition, $\mathrm{TpTG}_{\mathrm{Cl}}$ can form numerous hydrogen bonds with CNFs since imine groups and hydroxyl/carboxyl groups can both act as donor or acceptor of the hydrogen bonds ${ }^{26}$. We also performed all-atom molecular dynamics (MD) simulations to elucidate the assembly behavior. In the simulations, $\mathrm{CNF}$ s are placed nearby the $\mathrm{TpTG}_{\mathrm{Cl}}$ surface, and the nonbonded interactions are formed between $\mathrm{TpTG}_{\mathrm{Cl}}$ and $\mathrm{CNF}$ after the structure optimization. The results (Fig. 1h) show that electrostatic interaction is the main contributor towards the nonbonded interaction energy between $\mathrm{TpTG}_{\mathrm{Cl}}$ and CNFs. The hydrogen bond interactions also play a key role to facilitate assembly behavior.

Preparation of COF membranes. The COF membrane was fabricated by a vacuum-assisted self-assembly method on a polyacrylonitrile (PAN) substrate (Fig. 2a). The PAN substrate with an average surface pore size of $30 \mathrm{~nm}$ (Supplementary
Fig. 13) was uniformly deposited by a dense and defect-free $\mathrm{TpTG}_{\mathrm{Cl}} @ \mathrm{CNF}-\mathrm{X}$ membrane, as shown in SEM and AFM images (Fig. $2 \mathrm{~b}$ and Supplementary Fig. 14). The as-prepared $\mathrm{TpTG}_{\mathrm{Cl}} @ \mathrm{CNFs}-\mathrm{X}$ membranes are flexible and their thickness can be tuned from dozens of nanometers to a few microns by varying the volume of the filtrate (Fig. 2c and Supplementary Figs. 15 and 16). The cross-section TEM image of the $\mathrm{TpTG}_{\mathrm{Cl}} @ \mathrm{CNFs}-\mathrm{X}$ membrane reveals an obvious lamellar structure (Fig. 2d). For obtaining a free-standing TpTG $\mathrm{Cl}_{\mathrm{Cl}} @ \mathrm{CNFs-X}$ membrane, the TpTG $\mathrm{Cl}_{\mathrm{C}} @ \mathrm{CNFs-X}$ membrane with a thickness of more than $2 \mu \mathrm{m}$ was filtered on a hydrophobic poly (ether sulfone) (PES) microfiltration membrane (pore size is around 0.22 $\mu \mathrm{m})$. After drying, the free-standing membrane could be easily peeled off from the PES substrate and used for characterization. The PXRD pattern of the TpTG $\mathrm{Cl}_{\mathrm{Cl}} @ \mathrm{CNF}$-X membrane is shown in Supplementary Fig. 17, which also displays high intensity of (100) and (001) peaks of COF $\mathrm{TpTG}_{\mathrm{Cl}}$.

The pore size distribution and stability of the membranes. A schematic diagram of pore structures in the membranes is displayed in Fig. 3a. For the TpTG $\mathrm{Cl}_{\mathrm{C}} @ \mathrm{CNFs}-\mathrm{X}$ nanocomposites, the sheltering effect of CNFs reduces the size of pore entrance of 
a
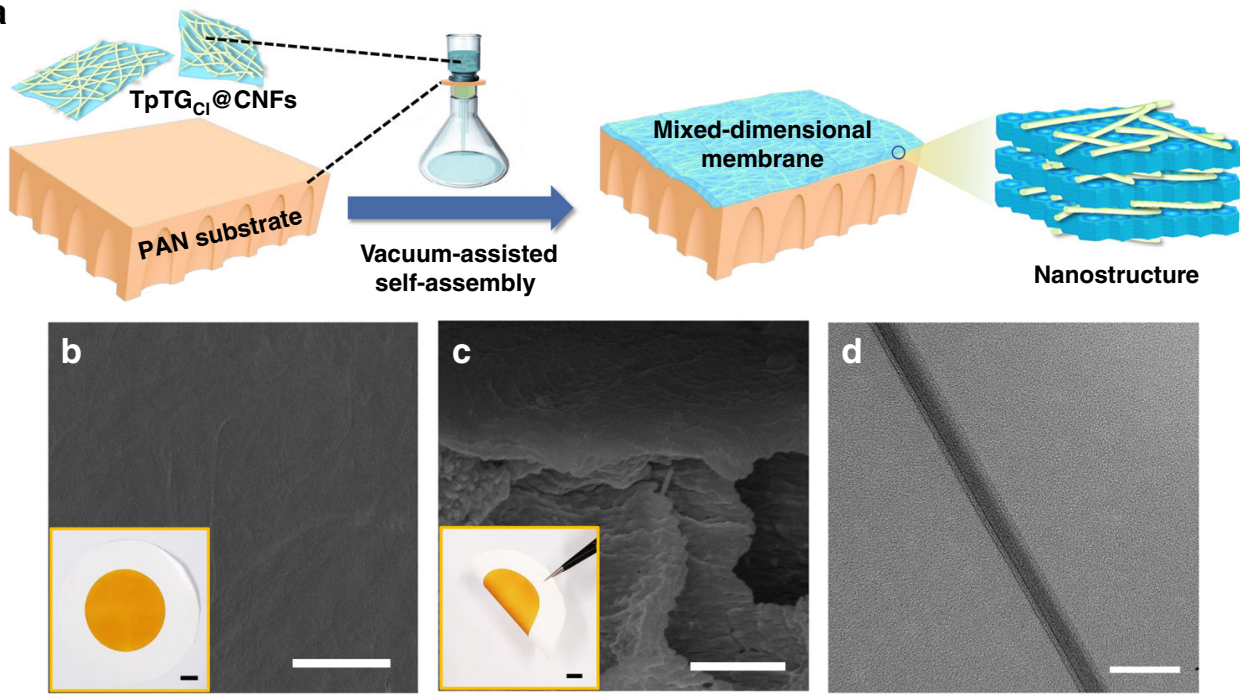

Fig. 2 Morphology of the membranes. a A schematic illustration showing the vacuum-assisted self-assembly and the mixed-dimensional nanostructure. b Surface SEM image of the TpTG $\mathrm{Cl}_{\mathrm{C}}$ CNFs-5/PAN membrane (scale bar, $1 \mu \mathrm{m}$ ) inserted with a digital photo of the membrane (scale bar, $1 \mathrm{~cm}$ ). c Cross-

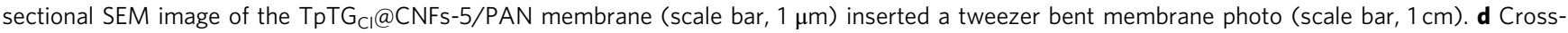
sectional TEM image of the TpTG $\mathrm{Cl}_{\mathrm{C}} @ \mathrm{CNFs}-5$ membrane (scale bar, 50 nm)

a

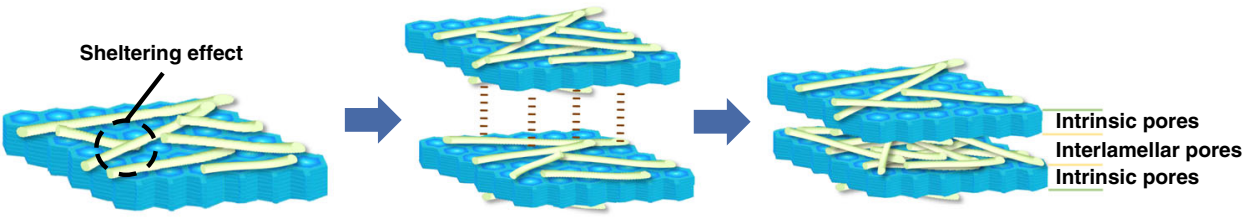

b

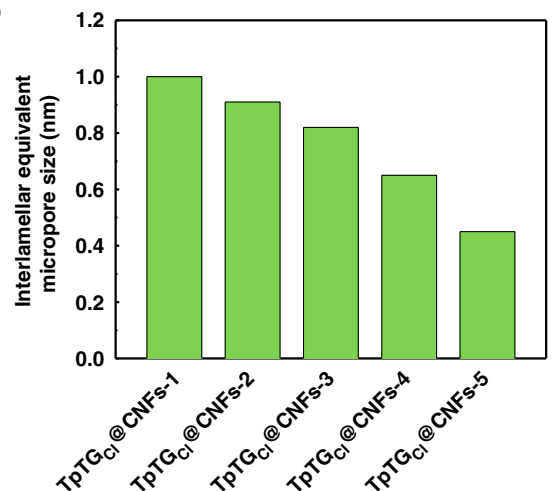

C

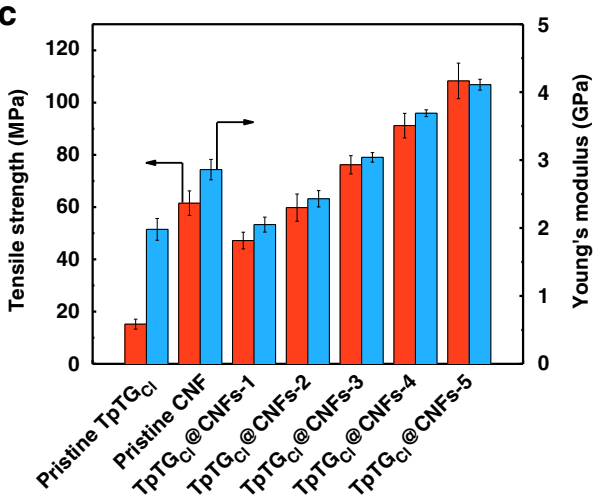

Fig. 3 Pore size distribution and mechanical strength of the membranes. a A schematic diagram showing the sheltering effect, interlamellar interactions and pore structures in the membranes. b The interlamellar equivalent micropore size of the TpTG $\mathrm{CI}_{\mathrm{C}} @ \mathrm{CNFs}-\mathrm{X}$ membranes. c The mechanical properties of the TpTG $\mathrm{Cl}_{\mathrm{C}} \mathrm{CNFs-X}$ membranes. Error bars represent standard deviations for 3 measurements

$\mathrm{TpTG}_{\mathrm{Cl}}$ framework. After assembling the TpTG $\mathrm{Cl} @ \mathrm{CNFs}$ nanocomposites into membranes, the interlamellar pores, consisting of network pores of CNFs, and pore entrance of $\mathrm{TpTG}_{\mathrm{Cl}}$ are formed. The pore size distributions of the membranes are demonstrated in Supplementary Fig. 18. For all membranes, the pore size distribution of $1.3 \mathrm{~nm}$ is derived from the intrinsic pores of $\mathrm{TpTG}_{\mathrm{Cl}}$. The pore size distribution of less than $1.3 \mathrm{~nm}$ is derived from the interlamellar micropores in membranes. With increasing CNF content in membranes, the number of interlamellar micropores increases while the interlamellar equivalent micropore size declines from 1.0 to $0.45 \mathrm{~nm}$ (Fig. 3b). The pore size distribution variation is mainly due to the interlocked CNF networks and the sheltering of CNFs on the nanopores of $\mathrm{TpTG}_{\mathrm{Cl}}$. This also manifests that the pore size distribution in the membranes could be effectively tailored to accomplish different molecular separations.

The mechanical properties of the free-standing membranes are shown in Fig. 3c. The TpTG $\mathrm{Cl}_{\mathrm{Cl}} @ \mathrm{CNFs}-\mathrm{X}$ membranes show much higher tensile strength (up to 108.3 MPa) and elastic modulus (up to $3.62 \mathrm{GPa}$ ) compared with the pristine $\mathrm{TpTG}_{\mathrm{Cl}}$ membranes and the pristine CNF membrane. The high mechanical properties of the $\mathrm{TpTG}_{\mathrm{Cl}} @ \mathrm{CNFs}-\mathrm{X}$ membranes are mainly attributed to the following three structural features: (i) the horizontal orientation of TpTG $\mathrm{Tl}_{\mathrm{Cl}}$; (ii) hydrogen-bonded parallel chains of $1 \mathrm{D}$ CNFs and (iii) the multiple interactions between $\mathrm{TpTG}_{\mathrm{Cl}}$ and $\mathrm{CNFs}^{27}$. Furthermore, the structures of the membranes are similar to the bee honeycombs in nature, which consists of multilayered hexagonal cells and fiber-like cell covers and exhibits excellent 
mechanical strength ${ }^{28}$. A fracture model is proposed to elucidate the enhancement of the mechanical strength of the membranes (Supplementary Fig. 19). For the pristine $\mathrm{TpTG}_{\mathrm{Cl}}$ membrane, the weak interlamellar $\pi-\pi$ interactions make it vulnerable when stretching. While for the TpTG $\mathrm{Cl}_{\mathrm{C}} @ \mathrm{CNFs}-\mathrm{X}$ membrane, the hydrogen bonds of CNF networks are initially broken, and then $\mathrm{CNF}$ are stretched and energy is dissipated 27 . On further stretching, the ionic bonds between $\mathrm{TpTG}_{\mathrm{Cl}}$ and $\mathrm{CNF}$ are broken and more energy is absorbed which brings about the fracture of the membrane. Thermogravimetric analysis (TGA) curves show the high thermal stability of the membranes, in which the weight loss can be as low as $5 \%$ when the temperature is below $200{ }^{\circ} \mathrm{C}$ (Supplementary Fig. 20). The chemical and solvent stability of the membranes were verified by the fact that the membranes remained intact even after $15 \mathrm{~d}$ of solvent or acid treatment. The PXRD analysis was performed on these treated membranes, which confirmed that the structures remained unaltered ${ }^{12}$ (Supplementary Fig. 21). The chemical resistance property of these membranes arises from the ketoenamine-based backbone of $\mathrm{TpTG}_{\mathrm{Cl}}{ }^{16}$, hydrogen-bonded chains of CNFs, and the multiple interactions between $\mathrm{TpTG}_{\mathrm{Cl}}$ and CNFs. Thus, these membranes can find many practical separation applications.

Water-selective permeation properties of the membranes. In industry, solvent dehydration is a frequently-used requisite purification process and it is commonly energy-intensive and costly, especially for the (near-) azeotropic systems such as water/alcohol mixtures ${ }^{29,30}$. The water-selective permeation properties of the membranes were tested by a pervaporation process (Supplementary Fig. 22) using water/alcohol binary mixtures (10 wt $\% / 90$ wt\%) under a strong $60 \mathrm{~L} \mathrm{~h}^{-1}$ cross flow. The separation performance of the membranes was optimized by manipulating the CNF content and the thickness of TpTG $\mathrm{Cl}_{\mathrm{C}} @ \mathrm{CNFs}-\mathrm{X}$ layer for different water/alcohol systems (Fig. 4a and Supplementary Fig. 23 and Supplementary Table 2). The C2-C4 alcohols were readily retained by the as-prepared $\mathrm{TpTG}_{\mathrm{Cl}} @ \mathrm{CNFs}-5 / \mathrm{PAN}$ membrane and the water concentration in permeate was higher than $99.5 \mathrm{wt} \%$, corresponding to separation factors $\left(\alpha_{\text {water/alcohol }}\right)$ higher than 2000. In particular, the high separation performance with a permeation flux of $8.53 \mathrm{~kg} \mathrm{~m}^{-2} \mathrm{~h}^{-1}$ and a $\alpha_{\text {water/n-butanol of }}$ 3876 was achieved for the water/n-butanol mixture. Compared with the TpTG $\mathrm{Cl}_{\mathrm{C}} \mathrm{CNFs}-5$ membrane, the membranes with fewer CNFs exhibit lower separation factor, and those with more CNFs exhibit lower permeation flux because the interlamellar equivalent micropore size in membranes decreases with the increasing CNF content. The effect of operation temperature on the separation performance of the TpTG $\mathrm{Cl}_{\mathrm{C}} @ \mathrm{CNFs}-5 / \mathrm{PAN}$ membrane was investigated, and the permeance and selectivity of the membranes were calculated (Supplementary Fig. 24). A long-term operation was carried out to assess the stability of the $\mathrm{TpTG}_{\mathrm{Cl}} @ \mathrm{CNFs}-5 /$ PAN membrane (Fig. 4b). The permeation flux was higher than 7 $\mathrm{kg} \mathrm{m}^{-2} \mathrm{~h}^{-1}$ and the water concentration in permeate was more than 99.8 wt $\%$ after $15 \mathrm{~d}$. The steady permeation flux and the high $a_{\text {water/n-butanol }}$ further confirm the high stability of the $\mathrm{TpTG}_{\mathrm{Cl}} @ \mathrm{CNFs}-5 / \mathrm{PAN}$ membrane in solvents and also demonstrate their potential in practical applications. Moreover, the TpTG $\mathrm{Cl}_{\mathrm{C}} @ \mathrm{CNFs}-5 / \mathrm{PAN}$ membrane in this study exhibits superior separation performance compared with the state-of-art membranes (including GO membrane, metal-organic framework (MOF) membrane, polymeric membrane, silica membrane and mixed matrix membranes) in the literatures (Fig. $4 \mathrm{c}$ and Supplementary Table 3$)^{4,29-44}$.

The water contact angle of the TpTG $\mathrm{Cl}_{\mathrm{C}} @ \mathrm{CNFs}-5 / \mathrm{PAN}$ membrane was measured to be $7.2^{\circ}$ and decreased to $\sim 0^{\circ}$ within only $0.2 \mathrm{~s}$ (Supplementary Fig. 25). The superhydrophilicity might have come from the synergistic effect of both high hydrophilicity and water uptake of $\mathrm{TpTG}_{\mathrm{Cl}}$ and CNFs. To verify this hypothesis, the surface roughness of the membranes and the water adsorption capacity of $\mathrm{TpTG}_{\mathrm{Cl}}$ and $\mathrm{CNFs}$ were measured as shown in Supplementary Figs. 26 and 27. The $\mathrm{TpTG}_{\mathrm{Cl}} / \mathrm{PAN}$ membrane shows a low average surface roughness $\left(R_{\mathrm{a}}\right)$ of 14.8 . When a droplet of water was brought in contact with the surface of the membrane, the advancing water contact angle appeared to be $29.3^{\circ}$. The water droplet quickly spread and permeated into the membrane within $0.2 \mathrm{~s}$. The ultrafast water permeation can be explained by the capillary effect of the membrane according to the Laplace theory (Equation (1)):

$$
P_{\mathrm{c}}=\Delta p=-2 \gamma \cos \theta_{\alpha} / R
$$

where $\Delta p$ is the liquid intrusion pressure, $\gamma$ is the surface tension of water in air, $\theta_{\alpha}$ is the advancing contact angle of the water on the surface, $R$ is the equivalent pore radius of the membrane. Since the $\theta_{\alpha}$ is $<90^{\circ}$, the calculated $P_{c}$ is $<0$. Meanwhile, the small pore size $(\sim 1.3 \mathrm{~nm})$ of $\mathrm{TpTG}_{\mathrm{Cl}} / \mathrm{PAN}$ membrane results in a large absolute value of $P_{c}$, which means that water is easy to permeate into the membrane with the capillary driving pressure of $P_{\mathrm{c}}$. The above analyses can well explain the fast water spreading ability. The CNFs/PAN membrane demonstrated a hydrophilic surface with an advancing water contact angle of $31.2^{\circ}$, which can be attributed to the high water adsorption capacity of CNFs (675 $\mathrm{cm}^{3} \mathrm{~g}^{-1}$ at $\left.P / P_{0}=0.9\right)$ and the rough surface $\left(R_{\mathrm{a}}\right.$ of 66.3$)$. However, the fast water spreading phenomenon was not observed for CNFs/PAN membrane which could be because the water permeation in CNFs was much slower than that in $\mathrm{TpTG}_{\mathrm{Cl}}$. The $\mathrm{TpTG}_{\mathrm{Cl}} @ \mathrm{CNFs}-5 / \mathrm{PAN}$ membrane shows a much smaller advancing water contact angle $\left(7.2^{\circ}\right)$ than the CNFs/PAN membrane $\left(31.2^{\circ}\right)$ and $\mathrm{TpTG}_{\mathrm{Cl}} / \mathrm{PAN}$ membrane $\left(29.3^{\circ}\right)$. There is no significant difference in surface roughness between the CNFs/ PAN membrane and TpTG $\mathrm{Cl}_{\mathrm{Cl}}$ CNFs-5/PAN membrane. Therefore, the low water contact angle for the $\mathrm{TpTG}_{\mathrm{Cl}} @ \mathrm{CNFs}-5 / \mathrm{PAN}$ membrane could be due to the synergy between $\mathrm{TpTG}_{\mathrm{Cl}}$ and CNFs. The TpTG $\mathrm{Cl}_{\mathrm{C}} @ \mathrm{CNFs}-5 / \mathrm{PAN}$ membrane integrates with both high water adsorption of CNFs and fast water spreading ability of $\mathrm{TpTG}_{\mathrm{Cl}}$, thus acquiring the smallest water contact angle. The superhydrophilic surface along with well-organized channels of the TpTG $\mathrm{Cl}_{\mathrm{Cl}} @ \mathrm{CNF}$-5/PAN membranes could remarkably lower the resistance for water permeation based on the solution-diffusion mechanism ${ }^{8,45}$. Furthermore, the suitable interlamellar equivalent micropore size $(0.45 \mathrm{~nm})$ endows the membranes with molecular sieving properties, which substantially prevents $\mathrm{n}$-butanol molecules (kinetic diameter of $0.51 \mathrm{~nm}$ ) from passing through the membrane.

A possible transport mechanism for water and n-butanol molecules across the membrane is depicted in Fig. 4d. Compared with n-butanol molecules, water molecules in the feed could be preferentially adsorbed on the superhydrophilic membrane surface. According to the water vapor adsorption-desorption isotherms in Supplementary Fig. 27, the water adsorption amount of $\mathrm{TpTG}_{\mathrm{Cl}}$ is higher than that of CNFs at a low relative pressure, thus the $\mathrm{TpTG}_{\mathrm{Cl}}$ on the surface could contribute more towards water adsorption than the CNFs. The feed would then rapidly transport through the well-organized channels of $\mathrm{TpTG}_{\mathrm{Cl}}$ in through-plane direction. The CNFs in the interlayer and the next $\mathrm{TpTG}_{\mathrm{Cl}}$ nanosheets can concentrate the water molecules to further enhance the solubility selectivity for water. Meanwhile, the interlamellar micropores with molecular sieving effects enhance the diffusion selectivity for water. The concentrated feed once again rapidly transports to the next interlayer through the nanopores in $\mathrm{TpTG}_{\mathrm{Cl}}$. After the repeated concentratingsieving process through the membrane, a high permeation flux along with a high water concentration in permeate is thus 


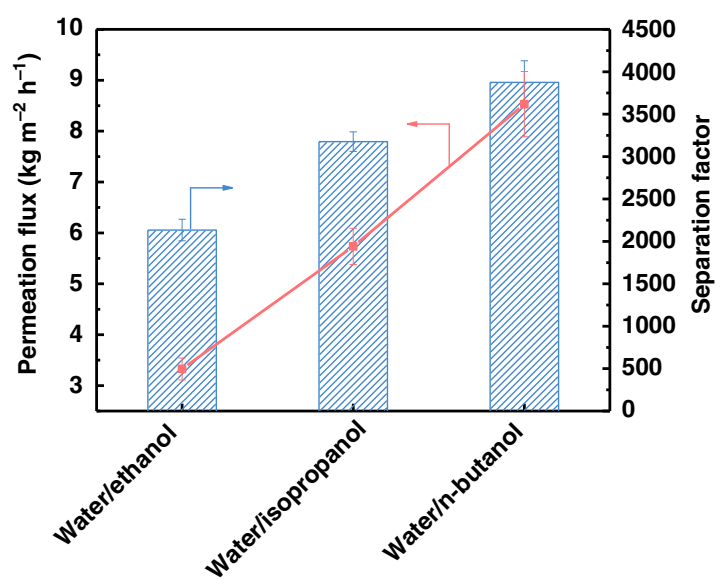

C

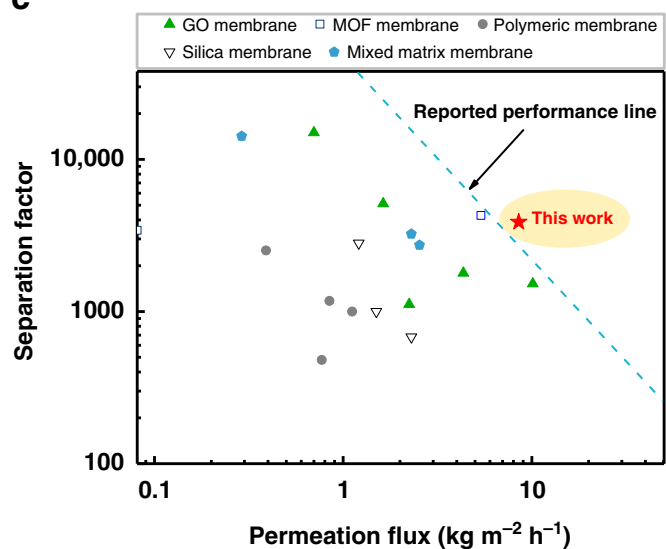

b

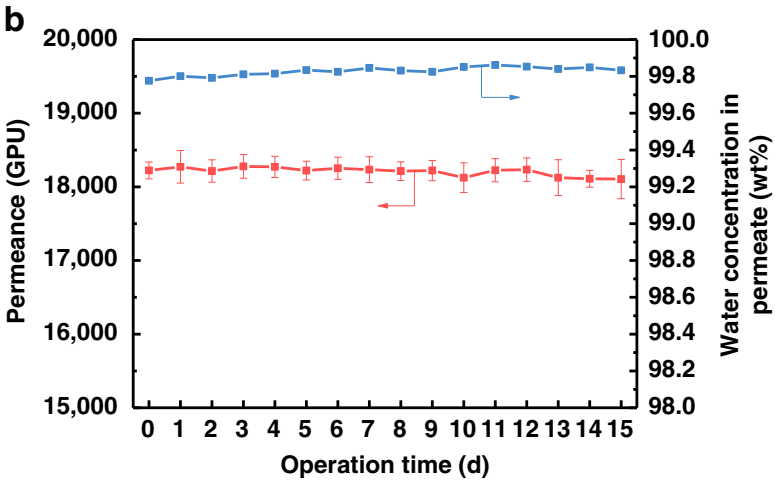

d

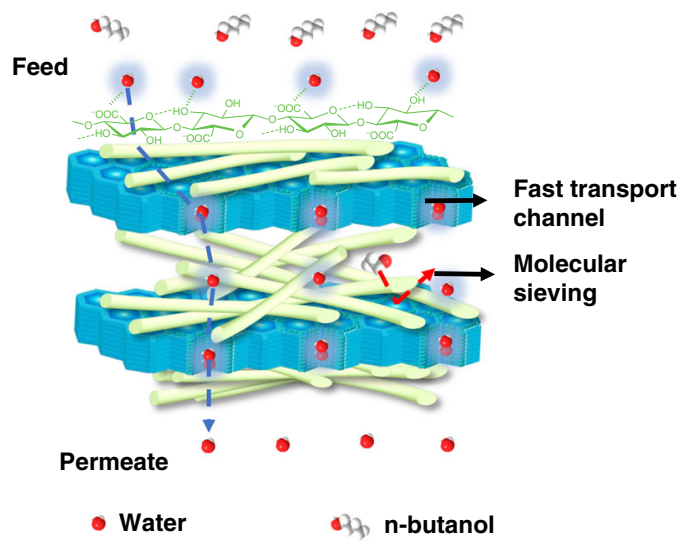

Fig. 4 Water-selective permeation properties of the membranes. a Separation performance of the TpTG $\mathrm{Cl}_{\mathrm{C}} \mathrm{CNFs-5/PAN}$ membrane with respect to different water/alcohol systems (water concentration: $10 \mathrm{wt} \%$ ). b Long-term separation performance of the membrane applied in a water/n-butanol system (water concentration: 10 wt\%; operating temperature: $80^{\circ} \mathrm{C}$ ). c Comparison of the water/n-butanol separation performance of the TpTG $\mathrm{Cl}_{\mathrm{C}} @ \mathrm{CNFs}_{\mathrm{N}}$ 5/PAN membrane and the representative membranes in the literatures. d A schematic diagram of the transport behavior of liquid molecules across the membrane. Error bars represent standard deviations for 3 measurements

achieved. The fast water transport of $\mathrm{TpTG}_{\mathrm{Cl}}$ was proved by $\mathrm{MD}$ simulations as shown in Supplementary Fig. 28, and a high confined water diffusion coefficient of $2.27 \times 10^{-7} \mathrm{~m}^{2} \mathrm{~s}^{-1}$ in $\mathrm{TpTG}_{\mathrm{Cl}}$ was calculated. To gain insight into the synergistic effect of $\mathrm{TpTG}_{\mathrm{Cl}}$ and $\mathrm{CNF}$, the pristine $\mathrm{TpTG}_{\mathrm{Cl}} / \mathrm{PAN}$ and pristine CNFs/PAN membranes were also fabricated and used for control experiments. As shown in Supplementary Fig. 29, the pristine $\mathrm{TpTG}_{\mathrm{Cl}} / \mathrm{PAN}$ membrane exhibits a high permeation flux but a very low separation factor due to the lack of molecular sieving. The pristine CNFs/PAN membrane exhibits both lower permeation flux and separation factor than those of the TpTG $\mathrm{Cl}_{\mathrm{Cl}} @ \mathrm{CNFs}$ 5/PAN membrane. Furthermore, another kind of membrane, denoted as $\left(\mathrm{TpTG}_{\mathrm{Cl}}+\mathrm{CNFs}\right) / \mathrm{PAN}$, was prepared by directly filtering the mixtures of individual $\mathrm{TpTG}_{\mathrm{Cl}}$ and $\mathrm{CNFs}$ and used for control experiments. Its separation performance was also not desirable due to the disordered molecular transport channels (Supplementary Fig. 30). It can be deduced that the mixeddimensional architecture not only endows the membranes with high mechanical strength, but also renders the membranes fast water-selective permeation properties.

Dye and salt rejection performance of the membranes. The previously reported works have indicated that the free-standing COF films show promise for nanofiltration applications ${ }^{9,46}$. Therefore, the application range of the TpTG $\mathrm{Cl}_{\mathrm{Cl}} @ \mathrm{CNFs}$-X/PAN membranes was further evaluated by nanofiltration. The pure water flux is nearly linear to the driving pressure, indicating the highly compact resistance of the membranes (Fig. 5a). The dye rejection performance of the membranes was evaluated by four dye solutions (congo red, alcian blue, methyl blue and orange GII) with a concentration of $100 \mathrm{ppm}$ (Fig. 5b and Supplementary Figs. 31 and 32). The $\mathrm{TpTG}_{\mathrm{Cl}} @ \mathrm{CNFs}-3 / \mathrm{PAN}$ membrane can reject congo red, alcian blue, methyl blue and orange GII with the rejection of $99.6,98.3,90.3$, and $90.3 \%$, respectively. The results demonstrate that the dyes with a size larger than $1 \mathrm{~nm}$ can be easily retained by the $\mathrm{TpTG}_{\mathrm{Cl}} @ \mathrm{CNFs}$-3/PAN membrane with an interlamellar equivalent micropore size of $0.82 \mathrm{~nm}$, and the permeance is higher than $70 \mathrm{~L} \mathrm{~m}^{-2} \mathrm{~h}^{-1} \mathrm{bar}^{-1}$. Compared with the TpTG $\mathrm{Cl}_{\mathrm{Cl}} @ \mathrm{CNFs}$-3/PAN membrane, the membranes with fewer CNFs have a lower rejection for dyes due to the larger interlamellar pore size. Although the membranes with more CNFs also have a high rejection for dyes, their permeance is much lower due to the densely packed CNF networks. Furthermore, the TpTG $\mathrm{Cl}_{\mathrm{C}} @ \mathrm{CNFs}-3 / \mathrm{PAN}$ membrane shows long-term stability up to $150 \mathrm{~h}$ for rejecting congo red as shown in Supplementary Fig. 33.

The salt rejection performance of the membranes was also evaluated as shown in Supplementary Fig. 34 and Fig. $5 \mathrm{c}$. The $\mathrm{TpTG}_{\mathrm{Cl}} @ \mathrm{CNFs}$-4/PAN membrane with an interlamellar equivalent micropore size of $0.65 \mathrm{~nm}$ exhibits a high rejection of $96.8 \%$ as well as high permeance of $42.8 \mathrm{~L} \mathrm{~m}^{-2} \mathrm{~h}^{-1} \mathrm{bar}^{-1}$, for $\mathrm{Na}_{2} \mathrm{SO}_{4}$. The hydration radii of $\mathrm{Cl}^{-}(0.66 \mathrm{~nm}), \mathrm{Na}^{+}(0.72 \mathrm{~nm})$, 


\section{a}
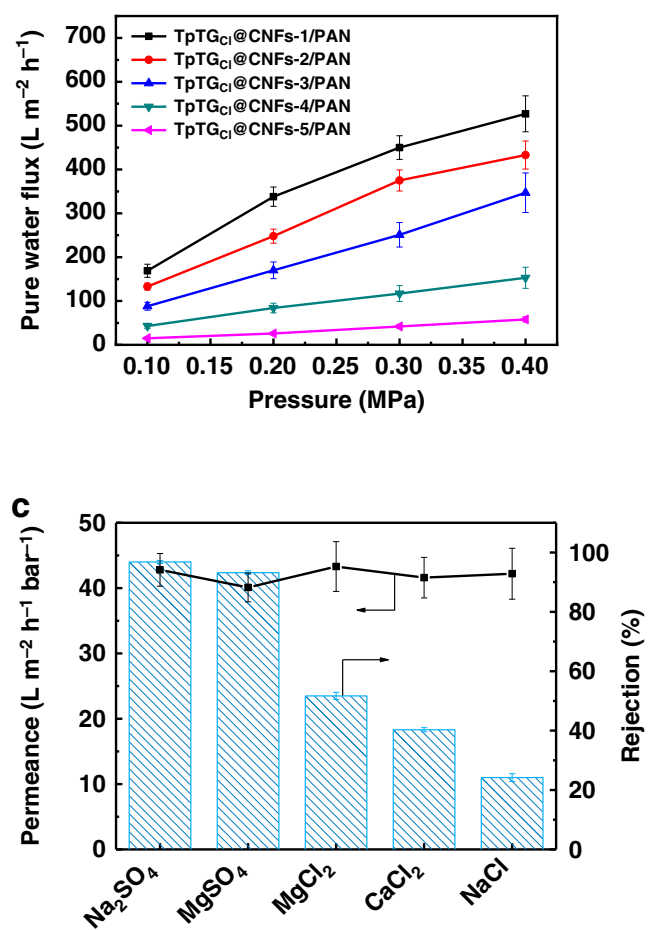

b

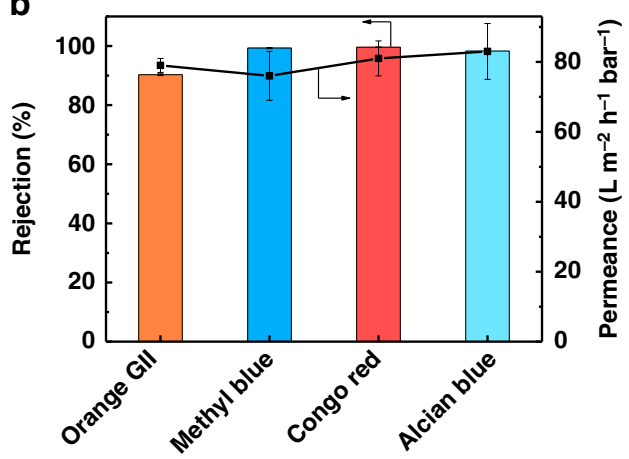

d

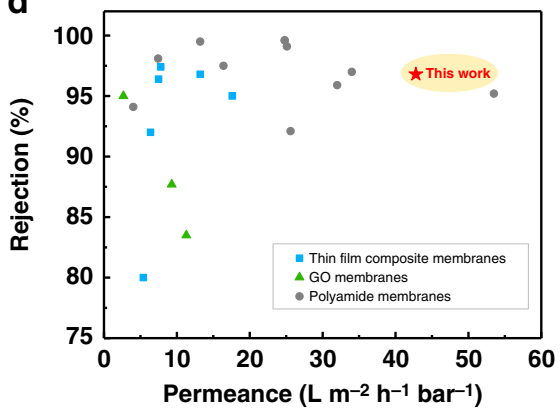

Fig. 5 Dye and salt rejection performance of the membranes. a Pure water flux of the TpTG $\mathrm{CI}_{\mathrm{C}} \mathrm{CNFs}-\mathrm{X} / \mathrm{PAN}$ membranes as a function of pressure. b Permeance and rejection of the TpTG $\mathrm{Cl}_{\mathrm{C}} @ \mathrm{CNFs}-3 / \mathrm{PAN}$ membrane for the nanofiltration of different dye solutions (dye concentration: 100 ppm; applied pressure: $0.2 \mathrm{MPa}$ ). c Permeance and rejection of the TpTG $\mathrm{Cl}_{\mathrm{C}} \mathrm{CNFs}-4 / \mathrm{PAN}$ membrane for the nanofiltration of different salt solutions (salt concentration: 1000 ppm; applied pressure: $0.4 \mathrm{MPa}$ ). d Comparison of the permeance and rejection of the $\mathrm{TpTG}_{\mathrm{Cl}} @ \mathrm{CNFs}_{\mathrm{S}} 4 / \mathrm{PAN}$ membrane and the representative membranes in the literatures for rejecting $\mathrm{Na}_{2} \mathrm{SO}_{4}$. Error bars represent standard deviations for 3 measurements

$\mathrm{SO}_{4}^{2-}(0.76 \mathrm{~nm}), \mathrm{Ca}^{2+}(0.82 \mathrm{~nm})$ and $\mathrm{Mg}^{2+}(0.86 \mathrm{~nm})^{47}$ are all larger than the pore size of $\mathrm{TpTG}_{\mathrm{Cl}} @ \mathrm{CNF}-4 / \mathrm{PAN}$ membrane. However, due to the broad pore size distribution, the ion rejection for $\mathrm{MgCl}_{2}, \mathrm{CaCl}_{2}$ and $\mathrm{NaCl}$ is not high enough. The rejection mechanism could be explained by a synergistic effect of size sieving and Donnan exclusion caused by the charged groups on the membrane surface to exclude the ions with the same charge. The cations could be attracted by the negatively charged membrane surface, which would lead to a concentration difference of ions in the solution and across the membrane, and a chemical potential difference would generate ${ }^{48}$. The Donnan exclusion effect for sulfate salts is more notable than that for chloride salts. Furthermore, the hydration radius of $\mathrm{Cl}^{-}$ $(0.66 \mathrm{~nm})$ is smaller than that of $\mathrm{SO}_{4}{ }^{2-}(0.76 \mathrm{~nm})$. Driven by this Donnan exclusion combined with steric hindrance, a high rejection for sulfate salts and a relatively low rejection for chloride salts are obtained. With the increase in CNF content, the amount of negatively charged groups on membrane surface increases while the interlamellar micropore size decreases. Therefore, the rejection for salts increases while the permeance decreases with the increase in CNF content. The high permeance for the TpTG $\mathrm{Cl}_{\mathrm{C}} @ \mathrm{CNFs}-4 / \mathrm{PAN}$ membrane is mainly attributed to the abundant water transport channels of $\mathrm{TpTG}_{\mathrm{Cl}}$. Furthermore, the TpTG $\mathrm{Cl}_{\mathrm{C}} @ \mathrm{CNFs}-4 / \mathrm{PAN}$ membrane also shows long-term stability up to $150 \mathrm{~h}$ for rejecting $\mathrm{Na}_{2} \mathrm{SO}_{4}$ as shown in Supplementary Fig. 35.

As shown in Supplementary Figs. 36 and 37, the pristine $\mathrm{TpTG}_{\mathrm{Cl}} / \mathrm{PAN}$ membrane shows a rejection of $85.7 \%$ for congo red and a rejection of $26.2 \%$ for $\mathrm{Na}_{2} \mathrm{SO}_{4}$, which are both lower than that of the TpTG $\mathrm{Cl}_{\mathrm{C}} @ \mathrm{CNF}$-X/PAN membrane (the highest congo red rejection of $99.6 \%$ and the highest $\mathrm{Na}_{2} \mathrm{SO}_{4}$ rejection of $96.8 \%)$. The high permeance but low rejection of the pristine $\mathrm{TpTG}_{\mathrm{Cl}} / \mathrm{PAN}$ membrane is due to the large intrinsic pore size $(1.3 \mathrm{~nm})$ of $\mathrm{TpTG}_{\mathrm{Cl}}$. The pristine $\mathrm{CNFs} / \mathrm{PAN}$ membrane shows a rejection of $88.1 \%$ for congo red and a rejection of $62.4 \%$ for $\mathrm{Na}_{2} \mathrm{SO}_{4}$, which illustrates that the CNFs alone cannot form appropriate pore size for effective dye or salt rejection. Furthermore, the $\left(\mathrm{TpTG}_{\mathrm{Cl}}+\mathrm{CNFs}\right) / \mathrm{PAN}$ membrane also exhibits inferior performance than that of the $\mathrm{TpTG}_{\mathrm{Cl}} @ \mathrm{CNFs}-\mathrm{X} / \mathrm{PAN}$ membrane due to the disordered molecular transport channels.

Compared with the performance of the representative nanofiltration membranes in the literatures (Fig. 5d and Supplementary Table 4$)^{48-66}$, the performance of TpTG ${ }_{\mathrm{Cl}} @ \mathrm{CNFs}-4 / \mathrm{PAN}$ membrane is comparable to most of the representative membranes for rejecting $\mathrm{Na}_{2} \mathrm{SO}_{4}$, and it can be applied at a much lower pressure. With regard to the rejection behavior for $\mathrm{NaCl}$, the as-prepared TpTG $\mathrm{Cl}_{\mathrm{C}} @ \mathrm{CNF} / \mathrm{PAN}$ membranes show a high ion selectivity to monovalent ions and divalent ions, demonstrating their potential application in salt rejection of solutions containing high concentration multivalent salts.

\section{Discussion}

We described the fabrication of COF membranes through a mixed-dimensional assembly of 2D COF nanosheets and 1D CNFs. This unique design resulted in the fast and highly selective water transport as well as the high stability of the membranes. This assembly strategy can also be applied to other 2D COFs to fabricate robust COF-based membranes. To further validate this idea, another four kinds of Schiff-base-type COFs i.e. TpPa-1, TpBD, TpHZ and $\mathrm{TpBD}(\mathrm{OH})_{2}{ }^{67-69}$ were synthesized by Tp and p-phenylenediamine (Pa-1), benzidine $(\mathrm{BD})$, hydrazine hydrate $(\mathrm{HZ})$, or 3,3'-dihydroxybenzidine $\left(\mathrm{BD}(\mathrm{OH})_{2}\right)$. The molecular structures and morphology of these COFs are shown in 
Supplementary Fig. 38. The structures of these COFs were confirmed by PXRD, ${ }^{13} \mathrm{C}$ CP-MAS solid-state NMR and FTIR as shown in Supplementary Figs. 39 and 40. These COF nanosheets were also assembled with CNFs to form stable COFs@CNFs nanocomposites by using the same method. Additional four kinds of membranes including TpPa-1@CNFs/PAN, TpBD@CNFs/ PAN,TpHZ@CNFs/PAN and TpBD $(\mathrm{OH})_{2} @ \mathrm{CNFs} / \mathrm{PAN}$ were fabricated and these membranes showed dense and defect-free structures (Supplementary Fig. 41). These membranes also display significantly improved mechanical strength compared with the corresponding pristine COF membrane as shown in Supplementary Table 5. Furthermore, these membranes could also exhibit high permeance as well as high rejection for dyes and salts, as shown in Supplementary Table 6.

In summary, we have explored a mixed-dimensional assembly strategy to design advanced COF membranes. The strategy of combining nanoporous $2 \mathrm{D}$ COFs with flexible and ultrastrong $1 \mathrm{D}$ CNFs solves the current separation performance-mechanical strength dilemma in COF membrane fabrication and its effective application for molecular separations. High separation performance of the membranes has been achieved in alcohol dehydration, dye rejection and salt rejection. The mechanical strength of the membranes has also been improved owing to the multiple interactions. The designable structures and extremely high stability of COFs offer an intriguing opportunity to develop advanced synthetic membranes. The mixed-dimensional design in our study can apply to fabricate a series of various COF membranes. These COF membranes have demonstrated high potentials in energy and environment-relevant separation processes such as solvent dehydration and water reuse.

\section{Methods}

General. The experimental materials and detailed synthesis procedure of COFs $\left(\mathrm{TpTG}_{\mathrm{Cl}}, \mathrm{TpPa}-1, \mathrm{TpBD}, \mathrm{TpHZ}\right.$, and $\left.\mathrm{TpBD}(\mathrm{OH})_{2}\right)$ are given in the Supplementary methods.

Preparation of the TpTG $\mathbf{T I}_{\mathbf{c l}} @ \mathbf{C N F s - X}$ nanocomposites. The $\mathrm{TpTG}_{\mathrm{Cl}}$ dispersion and $\mathrm{CNF}$ dispersion were prepared by using deionized water $(\mathrm{pH}=6.0)$. To fabricate the TpTG $\mathrm{Tl}_{\mathrm{Cl}} @ \mathrm{CNFs}-\mathrm{X}$ nanocomposites, a certain volume $(1,2,3,4,5,6$ or $7 \mathrm{~mL}$ ) of CNF dispersion ( $0.03 \mathrm{wt} \%$ ) was added into $25 \mathrm{~mL}$ of $\mathrm{TpTG}_{\mathrm{Cl}}$ dispersion $\left(0.5 \mathrm{mg} \mathrm{mL}^{-1}\right)$ with vigorous stirring for $12 \mathrm{~h}$ at $60{ }^{\circ} \mathrm{C}$. In this procedure, stable mixed-dimensional TpTG $\mathrm{Cl}_{\mathrm{Cl}} @ \mathrm{CNF}$-X nanocomposites with a planar TpTG $\mathrm{Cl}$ nanosheet uniformly encapsulated into a dense network of $1 \mathrm{D}$ nanofibers were formed through a self-assembly. The products were centrifuged at $10,000 \mathrm{rpm}$ for 15 min to remove the extra CNFs that could not bond with $\mathrm{TpTG}_{\mathrm{Cl}}$ surface. The resulted $\mathrm{TpTG}_{\mathrm{Cl}} @ \mathrm{CNF}$-X nanocomposites were dialyzed against deionized water for $5 \mathrm{~d}$ by a dialysis membrane tube with a molecular weight cut-off of 12,000, resulting in the stable dispersion of $\mathrm{TpTG}_{\mathrm{Cl}} @ \mathrm{CNFs}-\mathrm{X}$ nanocomposites.

Preparation of additional COFs@CNFs-X nanocomposites. Additional four kinds of mixed-dimensional nanocomposites including TpPa-1@CNFs-X, TpBD@CNFs-X, TpHZ@CNFs-X and TpBD $(\mathrm{OH})_{2} @ \mathrm{CNFs}-\mathrm{X}$ were also prepared by the same procedure as described above.

Preparation of the membranes. The PAN substrates were immersed in water for $2 \mathrm{~d}$ to remove any residues in the pores prior to use. The $\mathrm{TpTG}_{\mathrm{Cl}} @ \mathrm{CNF}$-X/PAN membranes were fabricated by filtering a certain volume $(5,10,30,100,250$, or $500 \mathrm{~mL})$ of the TpTG $\mathrm{Cl}_{\mathrm{C}} @ \mathrm{CNF}-\mathrm{X}$ solution $\left(0.005 \mathrm{mg} \mathrm{mL}^{-1}\right)$ on PAN substrates through a vacuum-assisted self-assembly method. The COFs@CNFs nanocomposites were stacked into membranes in one-step driven by the pressure and then the membranes were dried at $40{ }^{\circ} \mathrm{C}$ for $24 \mathrm{~h}$. The thickness of TpTG $\mathrm{Cl}_{\mathrm{Cl}} \mathrm{CNF}-\mathrm{X}$ membrane can be tuned by varying the volume of filtrate. The pristine $\mathrm{TpTG}_{\mathrm{Cl}} /$ $\mathrm{PAN}$ and pristine CNFs/PAN membranes were fabricated for comparison by filtering the alone $\mathrm{TpTG}_{\mathrm{Cl}}$ solution or alone CNF solution on PAN substrates, in which the contents of $\mathrm{TpTG}_{\mathrm{Cl}}$ and CNFs were equal to the corresponding $\mathrm{TpTG}_{\mathrm{Cl}} @ \mathrm{CNFs}-\mathrm{X} / \mathrm{PAN}$ membranes. The $\left(\mathrm{TpTG}_{\mathrm{Cl}}+\mathrm{CNFs}\right) / \mathrm{PAN}$ membranes were also fabricated for comparison by directly filtering the mixtures of $\mathrm{TpTG}_{\mathrm{Cl}}$ and CNFs on PAN substrates without a pre-assembly, in which the contents of $\mathrm{TpTG}_{\mathrm{Cl}}$ and CNFs were also equal to the corresponding TpTG $\mathrm{Cl}_{\mathrm{Cl}} @ \mathrm{CNFs}-\mathrm{X} / \mathrm{PAN}$ membranes. The TpPa-1@CNFs-X/PAN, TpBD@CNFs-X/PAN, TpHZ@CNFs-X/ $\mathrm{PAN}$ and $\mathrm{TpBD}(\mathrm{OH})_{2} @ \mathrm{CNFs}-\mathrm{X} / \mathrm{PAN}$ membranes were also prepared by the same procedure. For each type of membrane, at least three samples were prepared and tested to ensure the experimental reproducibility.

Characterization. TEM images and element distribution mappings were taken by a JEM-2100F device, the FFT and IFFT patterns were obtained from the Gatan DigitalMicrograph Software. XRD analysis was conducted by a D/MAX-2500 instrument with $\mathrm{Cu}-\mathrm{Ka}$ radiation. AFM images were observed by a multifunctional scanning probe microscope (NTEGRA Spectra). Zeta potentials were measured by a Nano ZS instrument with a $4 \mathrm{~mW}$ He-Ne laser. $\mathrm{N}_{2}$ adsorptiondesorption isotherms were collected by a Quantachrome Autosorbe-1 analyzer at $77 \mathrm{~K}$, the surface area and pore size distribution were calculated by BET and NL-DFT methods. SEM images were observed by a Nanosem 430 device. FTIR was carried out by a BRUKER Vertex 70 equipment. XPS was performed on an ESCALAB 250Xi instrument by using an Al-Ka radiation source. Solid-state $\mathrm{CP} / \mathrm{MAS}$ NMR spectrum was collected by a $300 \mathrm{MHz}$ Varian InfinityPlus spectrometer. Water vapor adsorption-desorption isotherms were collected by a VTISA + steam adsorption instrument at $298 \mathrm{~K}$. Water contact angles were tested by a JC2000D2M static contact angle goniometer (POWEREACH ${ }^{\oplus}$ ). TGA curves were collected by the NETZSCH 209 F3 equipment under a $\mathrm{N}_{2}$ atmosphere. The mechanical properties of the membranes were measured by an electronic tensile machine (WDW-2) at a stretching rate of $1 \mathrm{~mm} \mathrm{~min}^{-1}$.

Water-selective permeation measurements. The water-selective permeation properties of the membranes were performed by a homemade pervaporation membrane module. The effective membrane area was $8.5 \times 10^{-4} \mathrm{~m}^{2}$. At the upstream side of the membrane module, the feed mixture was circulated at a rate of $60 \mathrm{~L} \mathrm{~h}^{-1}$ by a gear pump, and the pressure at the downstream side was kept below $0.3 \mathrm{kPa}$ by using a vacuum pump. The vapor permeate was collected by a cold trap inserted in liquid $\mathrm{N}_{2}$ and weighed after a certain period of time. The products were analyzed by a gas chromatography (Agilent 7820A). The permeation flux ( $J, \mathrm{~kg} \mathrm{~m}$ ${ }^{-2} \mathrm{~h}^{-1}$ ) and separation factor $(\alpha)$ were calculated by Eqs. (2) and (3):

$$
\begin{gathered}
J=\frac{M}{S \times t}, \\
\alpha=\frac{P_{\mathrm{W}} /\left(1-P_{\mathrm{W}}\right)}{F_{\mathrm{W}} /\left(1-F_{\mathrm{W}}\right)},
\end{gathered}
$$

where $M$ represents the mass of permeate $(\mathrm{kg}), S$ is the membrane area $\left(\mathrm{m}^{2}\right)$, and $t$ refers to the time interval (h). $F_{\mathrm{W}}$ and $P_{\mathrm{W}}$ are the mass fraction of water in feed and permeate, respectively.

By eliminating the influence of partial pressure driving force, the permeance $((P / l), \mathrm{GPU})$ of the individual component was calculated by Equation (4) and the selectivity $(\beta)$ was calculated by Equation (5).

$$
\begin{gathered}
(P / l)_{i}=\frac{J_{i}}{p_{i 0}-p_{i l}}=\frac{J_{i}}{\gamma_{i 0} x_{i 0} p_{i 0}^{\text {sat }}-p_{i l}}, \\
\beta=\frac{(P / l)_{\mathrm{W}}}{(P / l)_{\mathrm{A}}},
\end{gathered}
$$

where $l$ refers to the membrane thickness (m). For individual component $i, J_{i}$ is the permeation flux $\left(\mathrm{kg} \mathrm{m}^{-2} \mathrm{~h}^{-1}\right), p_{i 0}$ and $p_{i l}$ are the partial pressure $(\mathrm{Pa})$ in the upstream side and the downstream side, respectively. $\gamma_{i 0}$ refers to the activity coefficient which is calculated by the Wilson equation. $x_{i 0}$ is the mole fraction in the feed and $p^{\text {sat }}{ }_{i 0}$ is the saturated vapor pressure obtained through the Antoine equation. Subscript W and A stand for water and alcohol, respectively.

Nanofiltration performance test. The separation test was carried out on a deadend vacuum filtration device with an effective membrane area of $4.9 \times 10^{-4} \mathrm{~m}^{2}$. Before testing, the membrane was compacted for more than $30 \mathrm{~min}$ at $0.2 \mathrm{MPa}$ to reach a steady state. The flux $\left(J, \mathrm{~L} \mathrm{~m}^{-2} \mathrm{~h}^{-1}\right)$ was calculated by Eq. (6), where the density $(\rho)$ of permeate is considered to be $1 \mathrm{~g} \mathrm{~cm}^{-3}$ due to the low dye/salt concentration. Permeance $\left(P, \mathrm{~L} \mathrm{~m}^{-2} \mathrm{~h}^{-1} \mathrm{bar}^{-1}\right)$ and rejection $(R, \%)$ of dyes or salts were calculated by Equation (7) and (8), where $\Delta p$ is the applied pressure, and $C_{\mathrm{p}}$ and $C_{\mathrm{f}}$ are the solute concentration in permeate and feed, respectively. UV-vis spectrophotometer (Hitachi UV-2800) and electrical conductivity (Leichi DDS11A) were used to determine the dye concentration and salt concentration, respectively.

$$
\begin{gathered}
J=\frac{M}{\rho \times S \times t}, \\
P=\frac{J}{\Delta p}, \\
R=\left(1-\frac{C_{\mathrm{p}}}{C_{\mathrm{f}}}\right) \times 100 \% .
\end{gathered}
$$

MD simulations. The MD simulations were performed by the Material Studio software. The models of $\mathrm{TpTG}_{\mathrm{Cl}}$ and CNFs were established based on the previous 
studies ${ }^{34,70}$. The structures of $\mathrm{TpTG}_{\mathrm{Cl}}$ and $\mathrm{CNFs}$ were optimized using the COMPASS force field and the non-bonded interaction energies were calculated based on a Dreiding force field. The non-bonded interactions include van der Waals forces, hydrogen bonds and electrostatic interactions. The van der Waals energy $E_{\mathrm{vdW}}$ and the hydrogen bond energy $E_{\mathrm{H}-\text { bond }}$ are described by the Lennard-Jones (12-6) and Lennard-Jones (12-10) potential, respectively. The electrostatic energy $E_{\text {Electrostatic }}$ is described by a screened (distance-dependent) Coulombic term and atomic monopoles. The non-bonded interaction energy $\Delta E$ between $\mathrm{TpTG}_{\mathrm{Cl}}$ and CNFs was calculated by Equation (9):

$$
\Delta E=E_{\mathrm{TpTG}_{\mathrm{Cl}} @ \mathrm{CNFs}}-\left(E_{\mathrm{Tp}_{\mathrm{TG}}}+E_{\mathrm{CNFs}}\right),
$$

where $E_{\mathrm{TpTG}_{\mathrm{Cl}} @ \mathrm{CNFs}}$ is the non-bonded energy of $\mathrm{TpTG}_{\mathrm{Cl}} @ \mathrm{CNFs}$ system, $E_{\mathrm{Tp} \mathrm{TG}_{\mathrm{Cl}}}$ and $E_{\mathrm{CNFs}}$ is the non-bonded energy of $\mathrm{TpTG}_{\mathrm{Cl}}$ and CNFs, respectively.

For the simulation of the water permeation through the $\mathrm{TpTG}_{\mathrm{Cl}}$ nanosheets, a thousand water molecules were placed in the chamber on one side (along the $\mathrm{z}$ direction) of the $\mathrm{TpTG}_{\mathrm{Cl}}$ as the feed chamber. The vacuum chamber was placed on the other side of the $\mathrm{TpTG}_{\mathrm{Cl}}$ as the permeate chamber. The $\mathrm{TpTG}_{\mathrm{Cl}}$ nanosheet of $3.15 \mathrm{~nm} \times 3.15 \mathrm{~nm}$ was placed in the simulated box, and a periodic boundary condition was applied to the $\mathrm{x}-\mathrm{y}$ direction. The $\mathrm{z}$ length of the simulation box was $11.0 \mathrm{~nm}$. The $\mathrm{TpTG}_{\mathrm{Cl}}$ nanosheets were modeled by the UFF force field with QEq charge ${ }^{71}$. The SPC/E model was used to describe water molecules ${ }^{72}$. In the diffusion simulation, the system was subjected to energy minimization using the smart minimizer method which switched from steepest-descent to conjugated gradient and then to the Newton method. Then, a 1 ns NVT (constant particle number, volume and temperature) simulation was performed with a time step of 1 fs. The Berendsen thermostat was employed to maintain the temperature of $353 \mathrm{~K}$. The atoms of the $\mathrm{TpTG}_{\mathrm{Cl}}$ were frozen in the simulation. Driven by the concentration gradient, water molecules in the feed chamber would pass through the pores of the $\mathrm{TpTG}_{\mathrm{Cl}}$ to the permeate chamber. The diffusion coefficients were calculated using the Einstein relation (Equation (10)):

$$
D=\lim _{t \rightarrow \infty} \frac{1}{6 t}\left(\frac{1}{N} \sum_{N}^{k=1}\left|r_{k}(t)-r_{k}(0)\right|^{2}\right),
$$

where $N$ is the number of molecules and $r_{k}(t)$ is the position of the $k$ th molecule at time $t$.

\section{Data Availability}

The source data underlying Figs. 1d, e, h, $3 \mathrm{~b}, \mathrm{c}, 4 \mathrm{a}, \mathrm{b}$ and $5 \mathrm{a}-\mathrm{c}$ are provided as a Source Data file. The data that support the findings of this study are available from the corresponding author upon reasonable request.

Received: 8 August 2018 Accepted: 24 April 2019

Published online: 08 May 2019

\section{References}

1. Novoselov, K. S. et al. Electric field effect in atomically thin carbon films. Science 306, 666-669 (2004).

2. Varoon, K. et al. Dispersible exfoliated zeolite nanosheets and their application as a selective membrane. Science 334, 72-75 (2011).

3. Kim, H. W. et al. Selective gas transport through few-layered graphene and graphene oxide membranes. Science 342, 91-95 (2013).

4. Huang, K. et al. High-efficiency water-transport channels using the synergistic effect of a hydrophilic polymer and graphene oxide laminates. Adv. Funct. Mater. 25, 5809-5815 (2015).

5. Morelos-Gomez, A. et al. Effective $\mathrm{NaCl}$ and dye rejection of hybrid graphene oxide/graphene layered membranes. Nat. Nanotechnol. 12, 1083-1088 (2017).

6. Diercks, C. S. \& Yaghi, O. M. The atom, the molecule, and the covalent organic framework. Science 355, eaal1585 (2017).

7. Huang, N., Wang, P. \& Jiang, D. L. Covalent organic frameworks: A materials platform for structural and functional designs. Nat. Rev. Mater. 1, 16068 (2016).

8. Fan, H. W., Gu, J. H., Meng, H., Knebel, A. \& Caro, J. High-flux membranes based on the covalent organic framework COF-LZU1 for selective dye separation by nanofiltration. Angew. Chem. Int. Ed. 57, 4083-4087 (2018).

9. Dey, K. et al. Selective molecular separation by lnterfacially crystallized covalent organic framework thin films. J. Am. Chem. Soc. 139, 13083-13091 (2017).

10. Joshi, R. K. et al. Precise and ultrafast molecular sieving through graphene oxide membranes. Science 343, 752-754 (2014).

11. Nair, R. R., Wu, H. A., Jayaram, P. N., Grigorieva, I. V. \& Geim, A. K. Unimpeded permeation of water through helium-leak-tight graphene-based membranes. Science 335, 442-444 (2012).
12. Kandambeth, S. et al. Selective molecular sieving in self-standing porous covalent-organic-framework membranes. Adv. Mater. 29, 1603945 (2017).

13. Li, G., Zhang, K. \& Tsuru, T. Two-dimensional covalent organic framework (COF) membranes fabricated via the assembly of exfoliated COF nanosheets. ACS Appl. Mater. Interfaces 9, 8433-8436 (2017).

14. Ying, Y. P. et al. A GO-assisted method for the preparation of ultrathin covalent organic framework membranes for gas separation. J. Mater. Chem. A 4, 13444-13449 (2016).

15. Zeng, Y., Zou, R. \& Zhao, Y. Covalent organic frameworks for $\mathrm{CO}_{2}$ capture. Adv. Mater. 28, 2855-2873 (2016).

16. Kandambeth, $\mathrm{S}$. et al. Construction of crystalline $2 \mathrm{D}$ covalent organic frameworks with remarkable chemical (acid/base) stability via a combined reversible and irreversible route. J. Am. Chem. Soc. 134, 19524-19527 (2012)

17. Kuhn, P., Antonietti, M. \& Thomas, A. Porous, covalent triazine-based frameworks prepared by ionothermal synthesis. Angew. Chem. Int. Ed. 47, 3450-3453 (2008)

18. Segura, J. L., Mancheno, M. J. \& Zamora, F. Covalent organic frameworks based on Schiff-base chemistry: synthesis, properties and potential applications. Chem. Soc. Rev. 45, 5635-5671 (2016).

19. Jariwala, D., Marks, T. J. \& Hersam, M. C. Mixed-dimensional van der Waals heterostructures. Nat. Mater. 16, 170-181 (2017).

20. Kontturi, E. et al. Advanced materials through assembly of nanocelluloses. Adv. Mater. 30, 1703779 (2018).

21. Ling, S. J., Kaplan, D. L. \& Buehler, M. J. Nanofibrils in nature and materials engineering. Nat. Rev. Mater. 3, 18016 (2018).

22. Wang, L. D. et al. Fundamental transport mechanisms, fabrication and potential applications of nanoporous atomically thin membranes. Nat. Nanotechnol. 12, 509-522 (2017).

23. Mitra, S. et al. Self-exfoliated guanidinium-based ionic covalent organic nanosheets (iCONs). J. Am. Chem. Soc. 138, 2823-2828 (2016).

24. Chen, H. W. et al. Cationic covalent organic framework nanosheets for fast Li-ion conduction. J. Am. Chem. Soc. 140, 896-899 (2018).

25. Isogai, A., Saito, T. \& Fukuzumi, H. TEMPO-oxidized cellulose nanofibers. Nanoscale 3, 71-85 (2011).

26. Shen, J. et al. Subnanometer two-dimensional graphene oxide channels for ultrafast gas sieving. ACS Nano 10, 3398-3409 (2016).

27. He, G. W. et al. Bioinspired ultrastrong solid electrolytes with fast proton conduction along 2D channels. Adv. Mater. 29, 1605898 (2017).

28. Mackenzie, D. Mathematics - Proving the perfection of the honeycomb. Science 285, 1338-1339 (1999).

29. Liu, X. L., Wang, C. H., Wang, B. \& Li, K. Novel organic-dehydration membranes prepared from zirconium metal-organic frameworks. Adv. Funct. Mater. 27, 1604311 (2017).

30. Yang, J. J. et al. Self-assembly of thiourea-crosslinked graphene oxide framework membranes toward separation of small molecules. Adv. Mater. 30, 1705775 (2018).

31. Tsou, C. H. et al. Effect of microstructure of graphene oxide fabricated through different self-assembly techniques on 1-butanol dehydration. J. Membr. Sci. 477, 93-100 (2015).

32. Shi, G. M., Yang, T. X. \& Chung, T. S. Polybenzimidazole (PBI)/zeolitic imidazolate frameworks (ZIF-8) mixed matrix membranes for pervaporation dehydration of alcohols. J. Membr. Sci. 415, 577-586 (2012)

33. Liu, T. et al. Preparation and characterization of polyelectrolyte complex membranes bearing alkyl side chains for the pervaporation dehydration of alcohols. J. Membr. Sci. 429, 181-189 (2013).

34. Zhang, G. J., Song, X., Ji, S. L., Wang, N. X. \& Liu, Z. Z. Self-assembly of inner skin hollow fiber polyelectrolyte multilayer membranes by a dynamic negative pressure layer-by-layer technique. J. Membr. Sci. 325, 109-116 (2008).

35. Widjojo, N. \& Chung, T. S. Pervaporation dehydration of C2-C4 alcohols by 6FDA-ODA-NDA/Ultem dual-layer hollow fiber membranes with enhanced separation performance and swelling resistance. Chem. Eng. J. 155, 736-743 (2009).

36. Xu, Y. M. \& Chung, T. S. High-performance UiO-66/polyimide mixed matrix membranes for ethanol, isopropanol and n-butanol dehydration via pervaporation. J. Membr. Sci. 531, 16-26 (2017).

37. Yang, $H$. et al. Hierarchical pore architectures from $2 \mathrm{D}$ covalent organic nanosheets for efficient water/alcohol separation. J. Membr. Sci. 561, 79-88 (2018).

38. Zhu, Y. X., Xia, S. S., Liu, G. P. \& Jin, W. Q. Preparation of ceramic-supported poly(vinyl alcohol)-chitosan composite membranes and their applications in pervaporation dehydration of organic/water mixtures. J. Membr. Sci. 349, 341-348 (2010).

39. Wang, Y., Goh, S. H., Chung, T. S. \& Na, P. Polyamide-imide/polyetherimide dual-layer hollow fiber membranes for pervaporation dehydration of C1-C4 alcohols. J. Membr. Sci. 326, 222-233 (2009).

40. Kalyani, S., Smitha, B., Sridhar, S. \& Krishnaiah, A. Blend membranes of sodium alginate and hydroxyethylcellulose for pervaporation-based enrichment of t-butyl alcohol. Carbohydr. Polym. 64, 425-432 (2006). 
41. Ben, B. et al. Pervaporation of binary water-alcohol and methanol-alcohol mixtures through microporous methylated silica membranes: Maxwell-Stefan modeling. Comput. Chem. Eng. 34, 1775-1788 (2010).

42. Verkerk, A. W., van Male, P., Vorstman, M. A. G. \& Keurentjes, J. T. F. Properties of high flux ceramic pervaporation membranes for dehydration of alcohol/water mixtures. Sep. Purif. Technol. 22-3, 689-695 (2001).

43. Huang, B. X., Liu, Q., Caro, J. \& Huang, A. S. Iso-butanol dehydration by pervaporation using zeolite LTA membranes prepared on 3aminopropyltriethoxysilane-modified alumina tubes. J. Membr. Sci. 455, 200-206 (2014).

44. Li, G. H., Shi, L., Zeng, G. F., Zhang, Y. F. \& Sun, Y. H. Efficient dehydration of the organic solvents through graphene oxide (GO)/ceramic composite membranes. RSC Adv. 4, 52012-52015 (2014).

45. Yang, H. et al. Functionally graded membranes from nanoporous covalent organic frameworks for highly selective water permeation. J. Mater. Chem. A 6, 583-591 (2018).

46. Matsumoto, M. et al. Lewis-acid-catalyzed interfacial polymerization of covalent organic framework films. Chem 4, 308-317 (2018).

47. Tansel, B. et al. Significance of hydrated radius and hydration shells on ionic permeability during nanofiltration in dead end and cross flow modes. Sep. Purif. Technol. 51, 40-47 (2006).

48. Wang, Z. Y. et al. Nanoparticle-templated nanofiltration membranes for ultrahigh performance desalination. Nat. Commun. 9, 2004 (2018).

49. Wu, H. Q., Tang, B. B. \& Wu, P. Y. Optimizing polyamide thin film composite membrane covalently bonded with modified mesoporous silica nanoparticles. J. Membr. Sci. 428, 341-348 (2013).

50. Hu, D., Xu, Z. L. \& Chen, C. Polypiperazine-amide nanofiltration membrane containing silica nanoparticles prepared by interfacial polymerization. Desalination 301, 75-81 (2012).

51. Zheng, J. F. et al. Sulfonated multiwall carbon nanotubes assisted thin-film nanocomposite membrane with enhanced water flux and anti-fouling property. J. Membr. Sci. 524, 344-353 (2017).

52. Tang, Y. J., Xu, Z. L., Huang, B. Q., Wei, Y. M. \& Yang, H. Novel polyamide thin-film composite nanofiltration membrane modified with poly (amidoamine) and $\mathrm{SiO}_{2}$ gel. RSC Adv. 6, 45585-45594 (2016).

53. Bano, S., Mahmood, A., Kim, S. J. \& Lee, K. H. Graphene oxide modified polyamide nanofiltration membrane with improved flux and antifouling properties. J. Mater. Chem. A 3, 2065-2071 (2015).

54. Xu, X. L. et al. Graphene oxide nanofiltration membranes stabilized by cationic porphyrin for high salt rejection. ACS Appl. Mater. Interfaces $\mathbf{8}$, 12588-12593 (2016).

55. Han, Y., Jiang, Y. Q. \& Gao, C. High-flux graphene oxide nanofiltration membrane intercalated by carbon nanotubes. ACS Appl. Mater. Interfaces 7 , $8147-8155$ (2015).

56. Chen, G. E. et al. Preparation and characterization of a composite nanofiltration membrane from cyclen and trimesoyl chloride prepared by interfacial polymerization. J. Appl. Polym. Sci. 132, 42345 (2015).

57. Chen, G. E. et al. Fabrication and characterization of a novel nanofiltration membrane by the interfacial polymerization of 1,4-diaminocyclohexane (DCH) and trimesoyl chloride (TMC). RSC Adv. 5, 40742-40752 (2015).

58. Tang, Y. J., Wang, L. J., Xu, Z. L., Wei, Y. M. \& Yang, H. Novel high-flux thin film composite nanofiltration membranes fabricated by the $\mathrm{NaClO}$ pre-oxidation of the mixed diamine monomers of PIP and BHTTM in the aqueous phase solution. J. Membr. Sci. 502, 106-115 (2016).

59. Pan, Y. Y. et al. Enhanced both perm-selectivity and fouling resistance of poly(piperazine-amide) nanofiltration membrane by incorporating sericin as a co-reactant of aqueous phase. J. Membr. Sci. 523, 282-290 (2017).

60. Tang, Y. J., Xu, Z. L., Xue, S. M., Wei, Y. M. \& Yang, H. A chlorine-tolerant nanofiltration membrane prepared by the mixed diamine monomers of PIP and BHTTM. J. Membr. Sci. 498, 374-384 (2016).

61. Zhu, Y. Z. et al. Single-walled carbon nanotube film supported nanofiltration membrane with a nearly $10 \mathrm{~nm}$ thick polyamide selective layer for high-flux and high-rejection desalination. Small 12, 5034-5041 (2016).

62. Wu, M. B. et al. Thin film composite membranes combining carbon nanotube intermediate layer and microfiltration support for high nanofiltration performances. J. Membr. Sci. 515, 238-244 (2016).

63. Yang, X., Du, Y., Zhang, X., He, A. \& Xu, Z. K. Nanofiltration membrane with a mussel-inspired interlayer for improved permeation performance. Langmuir 33, 2318-2324 (2017).
64. Wang, J. J., Yang, H. C., Wu, M. B., Zhang, X. \& Xu, Z. K. Nanofiltration membranes with cellulose nanocrystals as an interlayer for unprecedented performance. J. Mater. Chem. A 5, 16289-16295 (2017).

65. Zhu, J. Y. et al. Rapid water transport through controllable, ultrathin polyamide nanofilms for high-performance nanofiltration. J. Mater. Chem. A 6, 15701-15709 (2018).

66. Tan, Z., Chen, S. F., Peng, X. S., Zhang, L. \& Gao, C. J. Polyamide membranes with nanoscale Turing structures for water purification. Science 360, 518-521 (2018).

67. Kang, Z. et al. Mixed matrix membranes (MMMs) comprising exfoliated $2 \mathrm{D}$ covalent organic frameworks (COFs) for efficient $\mathrm{CO}_{2}$ separation. Chem. Mater. 28, 1277-1285 (2016).

68. Chandra, S. et al. Chemically stable multilayered covalent organic nanosheets from covalent organic frameworks via mechanical delamination. J. Am. Chem. Soc. 135, 17853-17861 (2013).

69. Karak, S., Kumar, S., Pachfule, P. \& Banerjee, R. Porosity prediction through hydrogen bonding in covalent organic frameworks. J. Am. Chem. Soc. 140, 5138-5145 (2018).

70. Fernandes, A. N. et al. Nanostructure of cellulose microfibrils in spruce wood. Proc. Natl Acad. Sci. 108, E1195-E1203 (2011).

71. Kadantsev, E. S., Boyd, P. G., Daff, T. D. \& Woo, T. K. Fast and accurate electrostatics in metal organic frameworks with a robust charge equilibration parameterization for high-throughput virtual screening of gas adsorption. J. Phys. Chem. Lett. 4, 3056-3061 (2013).

72. Berendsen, H. J. C., Grigera, J. R. \& Straatsma, T. P. The missing term in effective pair potentials. J. Phys. Chem. 91, 6269-6271 (1987).

\section{Acknowledgements}

This research was supported by the National Natural Science Foundation of China (No. 21490583, 21621004, 21878215, 21878216, 21576189), the State Key Laboratory of Organic-Inorganic Composites (No. oic-201801003).

\section{Author contributions}

H.Y., F.P., and Z.J. devised the idea. Z.X., Y.Z and Y.L. performed the experiments. H.W., L.Y., H.J.W., N.N. and Y.S. analyzed the data. H.Y., H.W., F.P., and Z.J. co-wrote the manuscript. All authors participated in the discussion and commented on the results.

\section{Additional information}

Supplementary Information accompanies this paper at https://doi.org/10.1038/s41467 019-10157-5.

Competing interests: The authors declare no competing interests.

Reprints and permission information is available online at http://npg.nature.com/ reprintsandpermissions/

Journal peer review information: Nature Communications thanks the anonymous reviewer(s) for their contribution to the peer review of this work. Peer reviewer reports are available.

Publisher's note: Springer Nature remains neutral with regard to jurisdictional claims in published maps and institutional affiliations.

(c) (i) Open Access This article is licensed under a Creative Commons Ay Attribution 4.0 International License, which permits use, sharing, adaptation, distribution and reproduction in any medium or format, as long as you give appropriate credit to the original author(s) and the source, provide a link to the Creative Commons license, and indicate if changes were made. The images or other third party material in this article are included in the article's Creative Commons license, unless indicated otherwise in a credit line to the material. If material is not included in the article's Creative Commons license and your intended use is not permitted by statutory regulation or exceeds the permitted use, you will need to obtain permission directly from the copyright holder. To view a copy of this license, visit http://creativecommons.org/ licenses/by/4.0/.

(C) The Author(s) 2019 